\title{
Research on Competitive Strategy-Case of DDL Construction Company
}

\author{
Suzhen Zeng \\ School of Management, Jinan University, Guangzhou, China \\ Email: szzengsuzhen@126.com
}

How to cite this paper: Zeng, S.Z. (2019) Research on Competitive Strategy-Case of DDL Construction Company. American Journal of Industrial and Business Management, 9, 743-763.

https://doi.org/10.4236/ajibm.2019.93049

Received: February 28, 2019

Accepted: March 24, 2019

Published: March 27, 2019

Copyright (c) 2019 by author(s) and Scientific Research Publishing Inc. This work is licensed under the Creative Commons Attribution International License (CC BY 4.0).

http://creativecommons.org/licenses/by/4.0/

(c) (i) Open Access

\begin{abstract}
With the reform of the construction industry in the country, the current dry engineering is becoming more and more difficult and the competition is becoming more and more fierce. At the same time, the slowdown of China's economic growth has also caused the construction industry's demand to slow down sharply. Faced with the dual pressures of deteriorating demand and increasing competition, how to find a solution is a strategic issue facing construction companies. This paper takes DDL Construction Company as the research object and conducts research on its competitive strategy, in order to provide support for the construction company to gain competitive advantage in such fierce competition. Through the relevant theories of strategic management and competitive strategy, this paper analyzes in detail the internal and external development environment and resource capabilities that DDL Construction Company face, and evaluates DDL Construction Company's development opportunities, threats, and its strengths and weaknesses. Based on this, SWOT matrix analysis and other methods are used to select suitable competitive strategies for DDL construction companies, and corresponding implementation safeguard measures are formulated.
\end{abstract}

\section{Keywords}

Construction Industry, Competitive Strategy, Focus Differentiation

\section{Introduction}

Since the 20th century, the competition of enterprises has become increasingly fierce. Business operations require systematic and scientific planning. Therefore, strategic thinking has been introduced into the field of business and enterprise management. By the middle and late 20th century, after the concept of corporate strategy was formally proposed, relevant research and theoretical works emerged 
one after another.

There are also many concepts about corporate strategy. Different researchers and managers define it from different angles, which means that there is no one-size-fits-all definition. The representative of the strategy is Henry Mintzberg's strategic 5P definition. He defines five definitions for strategy: First, strategy is a plan, which is a kind of conscious expectation. The process of activity, or a guideline for dealing with a situation; second, strategy is a pattern, that is, a pattern of behavior in a series of actions in the long run; third, strategy is a kind of positioning, that is, strategy is the intermediary power between the organization and the external environment, that is to say, through strategy, the organization must "match" with the environment, and from the perspective of management, that is, the product should be consistent with the market demand; fourth, strategy is an idea. (Perspective), an organization's unique "worldview", in management, that is, corporate philosophy; the final strategy is also a strategy to some extent, that is, the specific strategy adopted to confront and win the competition. Michael Porter believes that strategy is not just positioning, but creating a matching relationship between the various activities of the company. The success of the strategy depends on doing a lot of things and integrating them so that the strategy can be unique. Sex and persistence. Although these definitions are not identical, this is quite instructive for deepening the overall perception of the concept of corporate strategy.

In 1971, Kenneth R. Andrews, a professor at Harvard Business School in the United States, first raised questions about corporate strategic management. In his book "The Concept of Corporate Strategy", he divided strategic management into strategy formulation and strategy implementation. In the stage, the formulation and implementation of the strategy is the process of matching the advantages and disadvantages of the enterprise to the opportunities and threats in the environment. This is the classic SWOT analysis framework, which is a useful analytical tool for companies in strategic management.

In 1972, American scholar Ansoff officially proposed the concept of strategic management in his article "Strategic Management Thought", which further laid the foundation for strategic management theory. Ansoff believes that corporate strategic management is an enterprise that integrates long-term decision-making planning with its daily business. The entire strategic management process is an open system, which is a broader strategic management concept.

The famous American scholar Stana mentioned in his 1982 book "Enterprise Policy and Strategy" that corporate strategic management is essentially a dynamic process: first, to determine the mission of the enterprise, and then to analyze the internal and external environment of the enterprise., and its corporate mission as an important basis for the development of corporate goals, after the goal is set, to ensure that the objectives are correctly implemented, and ultimately achieve the corporate mission. This is a relatively narrow strategic management perspective.

In the book "Strategic Management Thoughts", Professor Fred R. David, a 
famous strategic management expert, defines strategic management as: to make an organization achieve its specific goals and formulate relevant comprehensive decisions, implementation and evaluation of science and art. And this paper takes DDL Construction Company as the main research object, analyzes its current business status, and provides recommendations for its competitive strategy in combination with competitive strategy theory. This article will be divided into the following parts: the second part will elaborate the theoretical basis used in this paper; the third part analyzes the internal and external environment of DDL company, and the fourth part summarizes the advantages and disadvantages of DDL based on the analysis results of the previous part, and Propose its competitive strategy; the fifth part provides specific implementation recommendations for DDL's focus differentiation strategy.

\section{Theory}

\subsection{Background}

One of the key points of corporate strategy is to gain competitive advantage, and the key to gaining competitive advantage is core competitiveness. The process of strategic management is actually the process of forming core competitiveness of enterprises and gaining competitive advantage. The so-called core competitiveness is the unique ability of the enterprise to form an irreplaceable business model that is difficult to be imitated by competitors and can maintain competitive advantage and stably obtain excess profits in the long run. In the theoretical field of competitive strategy, the more representative ones are the industrial organization school and the enterprise core competence school. This paper will analyze the theory of these two schools as the main theoretical basis.

\subsection{The School of Industrial Organization}

The representative of the Industrial Organization School is Professor Michael E. Porter of Harvard Business School, a well-known American competitive strategy expert. His book, Competition trilogy: "Competitive Strategy" [1], "Competitive Advantage" [2], "National Competitive Advantage" [3] laid the basic framework for the study of corporate competitive strategy theory. In his book, Porter presented the classic Porter five-force model, the value chain model, and three competing strategies. He believes that the formulation of corporate competition strategy will be affected by factors such as the fierce competition of the industry and the profitability of the industry, and these factors are often affected by the industrial structure. Therefore, if a company wants to develop a competitive strategy to obtain a corresponding competitive advantage, it must first analyze the industrial structure, that is, analyze the existing competitors of the enterprise, potential competitors who have not entered the industry, suppliers of the enterprise, and enterprises [3]. The strength of the five industries, the demand side and the substitute, evaluates the attractiveness of the industry. Based on the analysis of industrial structure, how can companies compete more effectively in 
order to strengthen their position in the market? Porter believes that it should further explore the favorable links in the enterprise value chain according to the analysis of industrial structure, and gain competitive advantage through three competitive strategic directions: total cost leading strategy, focusing strategy and differentiation strategy [4]. Companies should be guided by at least one of these strategies to develop specific competitive strategies to gain competitive advantage in the market.

After proposing the five-force model of industry structure analysis, Porter proposed value chain analysis. The competitive strategy based on industry structure analysis is more about considering the impact of market structure on the formulation of corporate competitive strategies, but not enough attention to the analysis of enterprises themselves. To make up for this deficiency, Porter proposed a value chain analysis tool.

Porter believes that "each company is a collection of activities that are designed, produced, sold, delivered and assisted in its products. All of these activities can be represented by a value chain". Value chain by value activities and the composition of profits. The basic point of the "value chain" analysis theory is that the competitive advantage of an enterprise actually comes from the value of the enterprise. Not all value chain links can create value [5] [6]. The value that enterprises actually create often comes from certain specific value creation activities. This is the so-called "strategic link". The competitive advantage of an enterprise is actually its advantage in certain value connections in the value chain. These strategic links that determine the business benefits of a company can be in the production of production links such as new product development, marketing, new technology development, etc., depending on the industry.

Porter believes that after conducting industrial structure analysis and internal value chain analysis, based on the results of the analysis, competitive advantages can be achieved through three alternative competitive strategies, namely, total cost leadership strategy, differentiation strategy, and focus strategy to gain a competitive advantage. Companies must choose one of these three strategies as their dominant strategy. Companies can choose to start with cost control and lower costs to lower than their main competitors; companies can also choose to differentiate themselves from their products and services, and be recognized by customers, so that customers get more value. Or the company can choose a particular market segment to serve the market, either in a differentiated strategy or a cost-leading strategy, or both. These three strategic architectures vary widely, and implementing them requires different resources and skills. Table 1 is a summary of the three competitive strategies.

\subsection{The School of Enterprise Core Competence}

The core competence school is actually a part of the basic resource school. The basic resources school believes that because resources are always limited in real economic life, if a company acquires a certain resource, this means that other 
Table 1 . The summary of the three competitive strategies.

\begin{tabular}{|c|c|c|c|}
\hline & Key points & Advantage & Disadvantage \\
\hline $\begin{array}{c}\text { Total cost } \\
\text { leadership strategy }\end{array}$ & $\begin{array}{l}\text { It is required to establish an effective and } \\
\text { optimal production scale, where the technology } \\
\text { of production facilities and production is the } \\
\text { key. At the same time, we must try our best to } \\
\text { reduce production costs and control } \\
\text { management costs on the basis of experience, } \\
\text { in order to minimize the total cost. }\end{array}$ & $\begin{array}{l}\text { 1) Higher income. } \\
\text { 2) Effectively defend against threats } \\
\text { from suppliers. } \\
\text { 3) Maintain substantial profits in the } \\
\text { fierce market and increase the chances } \\
\text { of survival. }\end{array}$ & $\begin{array}{l}\text { 1) Need higher market share } \\
\text { support. } \\
\text { 2) Need to know the cost of } \\
\text { competitors, it is difficult to do. }\end{array}$ \\
\hline $\begin{array}{l}\text { Differentiation } \\
\text { Strategy }\end{array}$ & $\begin{array}{l}\text { The aim is to provide customers with unique } \\
\text { benefits. This requires enterprises to have } \\
\text { strong innovation ability and high sense of } \\
\text { innovation. The innovative design and } \\
\text { production process of products must have } \\
\text { better innovation results, including brand } \\
\text { image, technology, product distribution } \\
\text { channels and so on. }\end{array}$ & $\begin{array}{l}\text { 1) High product prices will bring high } \\
\text { profit returns. } \\
\text { 2) It is difficult to be imitated. } \\
\text { 3) Product sustainable development. }\end{array}$ & $\begin{array}{l}\text { 1) It is often difficult to obtain a } \\
\text { high market share. } \\
\text { 2) High input costs and high } \\
\text { risks. }\end{array}$ \\
\hline Focus strategy & $\begin{array}{l}\text { The resources and strength of the centralized } \\
\text { enterprise focus on a specific customer group, } \\
\text { the market segment of a product series, etc., so } \\
\text { that the enterprise can better serve a narrow } \\
\text { segment of customers. }\end{array}$ & $\begin{array}{l}\text { 1) Gain a large competitive advantage } \\
\text { in a certain market segment and avoid } \\
\text { competing with too many competitors. } \\
\text { 2) Strong flexibility of strategy }\end{array}$ & $\begin{array}{l}\text { 1) The possibility of reducing } \\
\text { the cost of scale is small. } \\
\text { 2) The business risk is large and } \\
\text { is greatly affected by the outside } \\
\text { world. }\end{array}$ \\
\hline
\end{tabular}

companies will have fewer opportunities to obtain such resources, and they want to obtain sufficient resources [7]. The core competitiveness of the enterprise must be built. The core competence school believes that enterprises need to gain more competitive advantages by forming their own core capabilities. The core competence school is based on research on some of the best multinational companies of the time to present their views. Compared with the industrial organization school, the core competence school pays more attention to the enterprise itself, especially within the enterprise. Prahalad and Hamel published "The Core Competitiveness of the Company" in the Harvard Business Review in 1990, becoming the iconic work of the school. The school emphasizes the core competencies that enterprises embody in the production and operation process, and enterprises should use this as the basis for formulating competitive strategies. Specifically, it is to develop and implement the company's competitive strategy based on identifying, cultivating, applying and improving the unique capabilities of the company's internal production and operation and its processes.

In general, the core competence school believes that the enterprise competition strategy is not only the competition of products at the market level, but also the key link of core competitiveness management such as the identification, cultivation, diffusion and application of core competitiveness [8]. The core competence school failed to propose a specific competitive strategy analysis tool. However, the core competence school cultivates the core competitiveness of enterprises from the core competence identification, enterprise opportunity space analysis, core competence training, core competence application, and selection 
of partner leverage. This also provides a good idea for the development of the company's competitive strategy.

\section{Research Results of DDL Company}

\subsection{Analysis of DDL Company's External Environment}

Analysis of the macro environment will help enterprises to better grasp the changing trend of the macro environment and find out the opportunities and threats faced by enterprises. This can provide corresponding decision-making basis for the company's strategy formulation and adjustment. PEST analysis is a common method of macro-environment analysis. The PEST analysis method is composed of four parts: political, economic, social and technological environment analysis.

Political environment analysis. At present, the relevant regulatory system of China's construction industry is still not perfect. The industry supervision mode has a planned economy color, heavy examination and approval, light supervision, and the level of supervision and informationization is not high. The construction of market supporting mechanisms such as engineering guarantee, engineering insurance and credit management is progressing slowly. The market mechanism has insufficient role in the industry's access to clearing and survival of the fittest, which seriously affects the development vitality of the construction industry and the efficiency of resource allocation.

Economic environment analysis. The economic operation reflects the development of construction enterprises to a certain extent. The economic environment analysis mainly considers the economic characteristics, economic linkages, and economic conditions that affect the formulation and adjustment of corporate strategies. The economic conditions of a country or region where a construction company is located have a direct impact on the business activities of the company. As China's economy enters a new normal, China's economic growth has shifted from high-speed to medium-high speed, and GDP's average annual growth has continued to fall from around $10 \%$ in the early years to around $7.0 \%$ (Figure 1). Over the years, China's fixed asset investment in the whole society has maintained a growth rate of around $25 \%$ for many years, especially the development of the real estate market, which has brought market opportunities to the construction industry and the construction industry has developed rapidly. But in recent years its growth rate has begun to decline (Figure 2). Factors such as financial deleveraging, corporate deleveraging, and tightening of financially coordinated regulatory policies will all affect the sources of funding for fixed-asset investment, putting pressure on investment growth. Although China's economic growth has begun to slow down, the quality and efficiency of growth are improving. That is to say, China's economy will shift from scale-type extensive growth to quality-efficiency-type intensive growth, from factor-driven investment to innovation-driven. When economic growth is strong, it means that construction companies will usher in more development opportunities. 


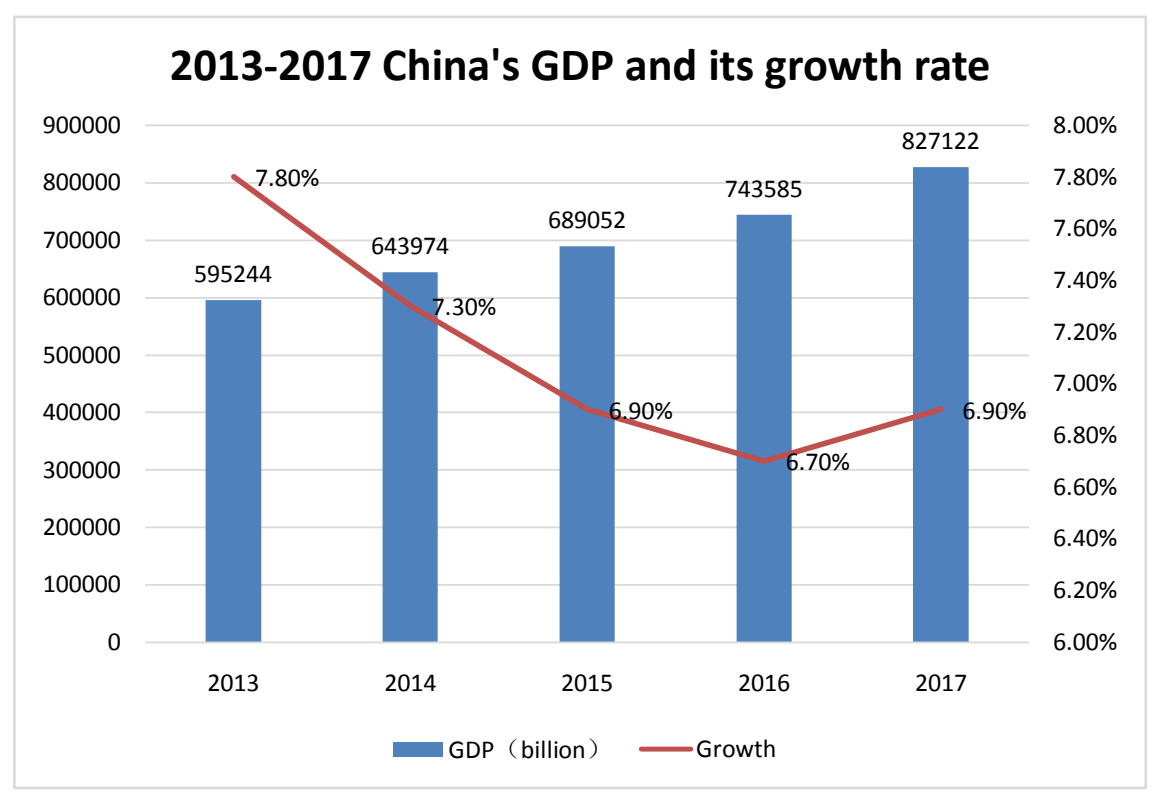

Figure 1. 2013-2017 China's GDP and its growth rate.

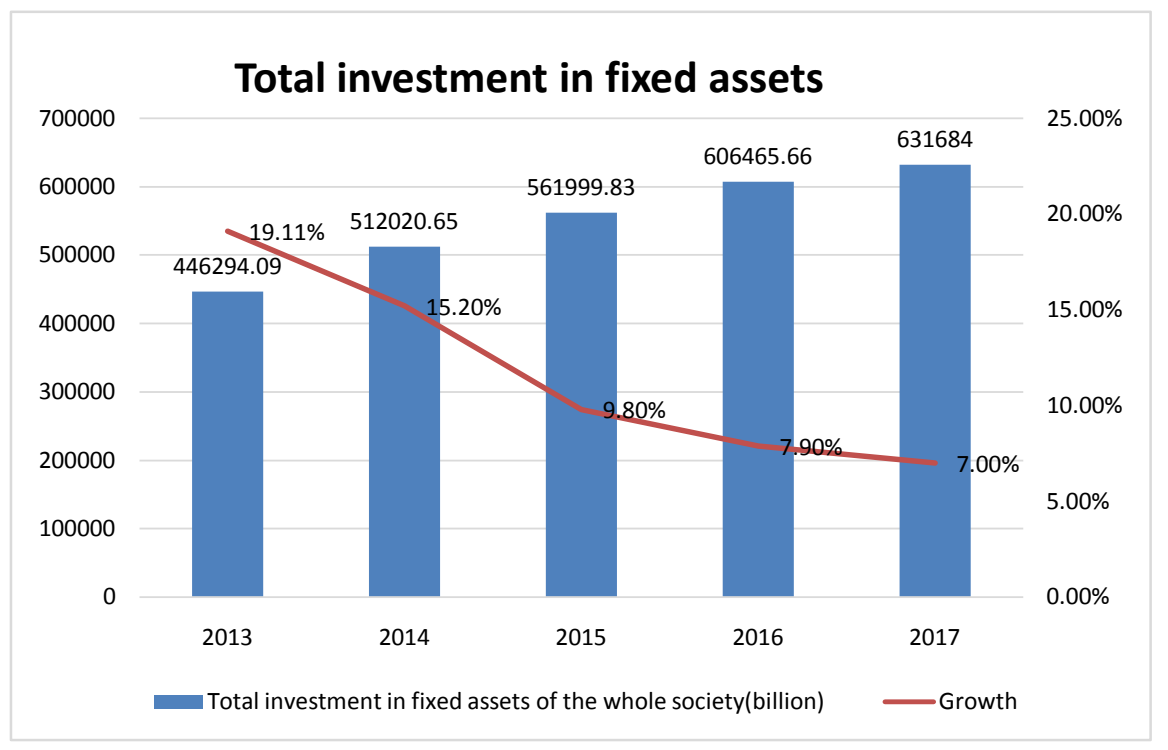

Figure 2. 2013-2017 total investment in fixed assets of the whole society and its growth rate.

Conversely, when economic growth slows down, the market opportunities of construction companies may decrease, affecting the further development of the construction industry. Under the background of the gradual slowdown of China's economic growth and the decline in the growth rate of total fixed asset investment in the whole society, the development speed of China's construction industry has also shown a slowing and stable trend (see Figure 3). Therefore, Although China's economic growth rate is slowing down at this stage, in fact, the quality and efficiency of China's economic growth are improving. From the perspective of the structure of fixed-asset investment, China's economic 


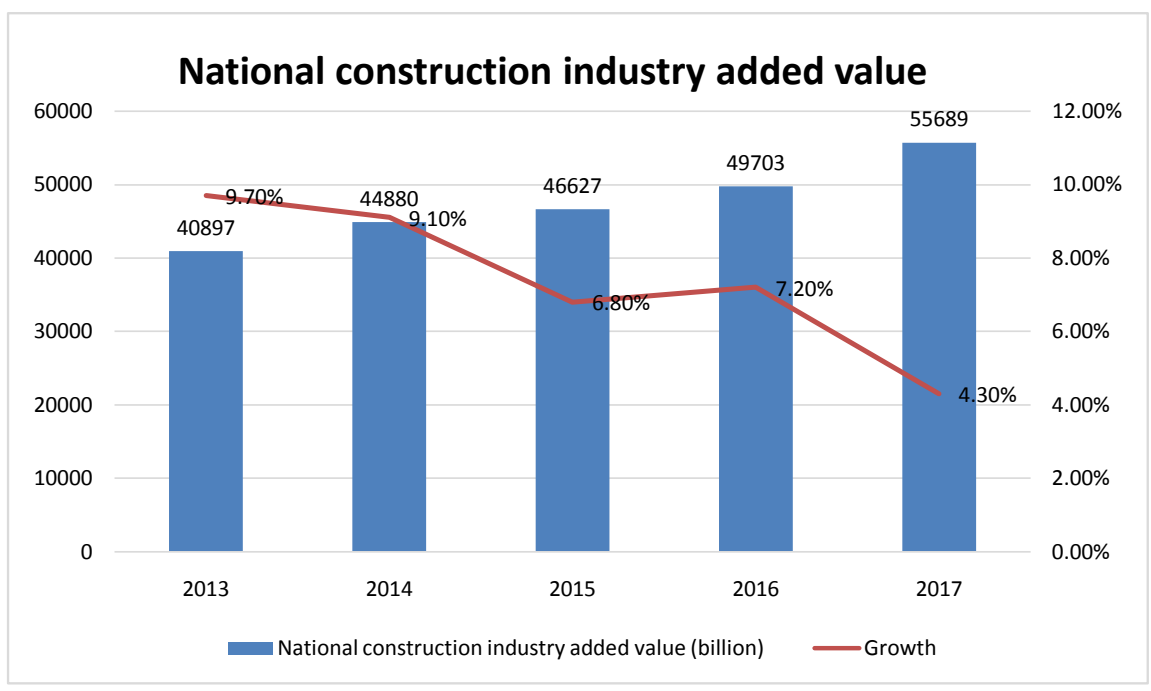

Figure 3. 2013-2017 National construction industry added value and its growth rate.

development can be more important to quality and balance, and this is in a certain To a certain extent, it means that there are more opportunities for infrastructure construction than real estate construction and housing construction. Under the current new economic normal, construction companies should adapt to the economic situation, adjust their business strategies in a timely manner, change the extensive development mode of the past, pay more attention to talents and technology, improve efficiency, actively carry out transformation and upgrading, and become specialized and intensive. The development of the road ahead, further improve the quality of supply, and discover new markets, so that it is possible to gain competitive advantage and achieve development in the fierce market competition, which is especially important for many small and medium-sized construction enterprises.

Social environment analysis. With the development of social economy, China is gradually realizing urbanization and industrialization, but at the same time, it has also caused problems such as environmental pollution and ecological damage. These problems threaten the sustainable development of China's social economy. The construction industry is an industry with large energy consumption and high pollution. Once the extensive development of China's construction industry has had a certain impact on the environment, such as construction waste, construction noise, etc., some buildings and facilities still have unreasonable design problems. Nowadays, concepts such as green buildings and smart buildings have emerged in an endless stream, reflecting the higher requirements for the green, environmentally friendly and safe production of the construction industry, and paying more attention to whether the construction process is green, energy-efficient, and safe. Reliable, this is worth noting for construction companies.

Technological environment analysis. The rapid development of emerging information technologies such as the Internet of Things, big data, artificial intelligence, and augmented reality technology has brought tremendous changes to 
many industries. The application of these technologies will also have far-reaching impact on the construction industry. Building Information Model (BIM) technology is built on the basis of many new information technologies. It is a model of information technology in the construction industry. It can provide comprehensive engineering data information from design, construction, and management to maintenance of the entire construction project, which is convenient for enterprises to carry out construction management according to data and improve efficiency. Besides, the new building materials are a new generation of building materials based on traditional building materials. Although traditional building materials still occupy most of the building materials market, and may still be mainstream for a long time, with the development of economic development and new technologies, new building materials have begun to appear. These new building materials are more environmentally friendly, safer and less expensive than many traditional building materials, and can be better integrated into the modern building industry. Now, some new wall materials, thermal insulation materials, waterproof sealing materials and decorative materials have appeared on the market, such as eart DDL uake-resistant structural steel, new artificial wheat straw board, fire-resistant color steel plate, and steam-free foam concrete block brick. Waterproof composite stone flooring and so on. It is foreseeable that new building materials will gradually occupy more and more market share in the future construction market.

\subsection{Analysis of DDL Company's Internal Environment}

1) Technical skills

Enterprise technical capability is the basis of daily production activities of the enterprise. It is the integration of multiple capabilities, covering all aspects and various aspects of the production and operation activities of the enterprise. In a market environment full of uncertainty, enterprise technology capability is an important manifestation of its competitiveness [9], and the different technological capabilities it possesses produce heterogeneity among enterprises. This study will comprehensively analyze the technical capabilities of DDL Construction Company from the two dimensions of construction technology capability and technological innovation capability.

For construction companies, construction technology and management is the company's most technical capacity module, and also the main source of core competitiveness. The ability level in this module is the absolute embodiment of the soft power of construction companies. In terms of DDL construction company's construction technology and management capabilities, first of all, from the perspective of construction management, all the DDL construction company's engineering projects can be promoted and completed on schedule, there has never been a "unfinished" project, and no progress has been made with customers. The problem of conflict. However, the production of this gratifying result is only small in terms of the current business volume of the company. In fact, the current project management of the company is weak, the project management 
department is ineffective, the substantive supervision and management is not deep, and the process evaluation of the project flows in form. Further, from the perspective of engineering qualification rate, it reflects the quality status of the completed and delivered engineering projects, and is a direct data representation of the company's construction technology capabilities. Different parts of different parts of a project must guarantee different quality requirements, and the overall quality of a project can be guaranteed. DDL Construction Company's engineering qualification rate is $100 \%$, which indicates that the company's quality is trustworthy, its construction technology is guaranteed, and it also reflects its good market reputation and customer satisfaction.

Enterprise technology innovation capability is an important guarantee for enterprises to form long-term competitive advantage. Innovation-driven development can maintain the core vitality of enterprises. For building enterprises, the innovation of construction technology and materials often requires large-scale capital and human resources. Due to the short time and small scale of DDL construction companies, there is currently little investment in this area. In the future, as the business continues to expand, the company should pay attention to $R \& D$ investment and strengthen technological innovation and innovation.

2) Marketing skills

Compared with the fast-moving retail industry, engineering and construction products have the characteristics of individualized demand, one-time production, and single-piece production. The impact of marketing ability on corporate profitability is not as prominent as the fast-moving retail industry. However, in recent years, the construction market has gradually It tends to be saturated, competition among enterprises is intensifying, and the importance of marketing is becoming more and more prominent, which has become one of the factors that constitute the core competitiveness of enterprises.

First, the company has not established a special marketing department and the marketing system is not perfect. The marketing activities of the company are handled by the budget department of the operation department, and the comprehensive office is responsible for corporate image packaging and external publicity. The project managers are responsible for the maintenance and after-sales service of existing customers. The process of the company's marketing activities is not continuous, and the resources are not fully utilized, resulting in the dispersion of marketing capabilities.

Second, the company's senior management valued bidding and neglected marketing. The company's senior leaders will focus on project bidding, a large amount of resources focused on the preparation of tenders, lack of research on customers, competitors and other stakeholders. Further, the price strategy for each project bidding has not been fully considered. Therefore, the company's bidding rate in actual projects is not satisfactory.

Third, the company's marketing method is single and its level is weak. In the case that the company's overall competitiveness is not strong, DDL Construction Company has not launched market research and segmentation of the construc- 
tion industry in Chifeng City, nor has it established a professional team to analyze and consolidate the market positioning of the company. The management of the company's management of shopping malls only stays in the gift-giving, pull relationship, lack of customer-oriented customer relationship management mechanism. At the same time, in the public relations communication, DDL Construction Company did not pay enough attention to corporate image design and brand promotion, which made the company lack local awareness.

3) Informatization ability

Informatization is the trend of enterprise technology and management transformation. Effective information architecture is conducive to enterprises to optimize business processes, reduce operational risks, reduce operating costs, and help enterprises to develop profitable space. At present, DDL construction company has a poor degree of informationization, and has not yet established an OA information management platform. Project teams in various departments cannot achieve effective communication.

Therefore, based on the summary of DDL's external environment and internal capabilities, we conduct SWOT analysis on the company. The company currently has the following strengths, weakness, opportunities and threats:

Strengths. First, being in the development stage, the growth momentum is good.

DDL Construction Company was established only four years ago. Whether it is the quantity and quality of project contracting or financial data, the company is in a steady development stage. Moreover, as a young company, DDL Construction's entrepreneurial team is united and collaborative, determined to forge ahead, whole staff struggle, work together, and dare to explore, and strive to achieve the company's established goals. Top management is far-sighted, with both strategic thinking for long-term development of the company and super-executive power for short-term operations. Second, high quality of the project. DDL Construction Company emphasizes quality assurance and still maintains $100 \%$ engineering completion rate. Its quality has been recognized by inspection departments and customers, far stronger than other private enterprises. Third, Excellent service level. DDL Construction has always established a mature system of business return process and system based on customer satisfaction. Through business return visits, help to understand customer opinions and needs, identify project problems through customer feedback, timely organize technical personnel to provide quality assurance services, and provide reasonable maintenance advice to customers to extend the life of the building. Fourth, good cooperation with customers and high reputation. Last but not least, strong sense of innovation.

Weakness. First, DDL company was established in a small period of time. For construction companies, the size and strength of the company are directly proportional. When the scale is small, the funds and resources of the company are limited and the strength is small. Second, there are still many problems in the 
management of the company. First, the level of DDL information management is low, and processes such as resource flow, business processing, and customer interaction have not yet formed a system, and the efficiency of enterprise business processing is affected. Second, human resources management is not good. The construction of the recruitment process, training process, performance appraisal and other processes is not perfect, resulting in high brain drain rate and enthusiasm of employees. Third, management power is too concentrated. Many of the control functions of DDL Construction Company are controlled by the general manager. It is difficult for employees to participate in decision-making, and the control functions are ineffective. Third, DDL Construction Company has tight cash flow and weak investment and financing capabilities. Therefore, most of the businesses it undertakes are in areas with small profit margins, with small scale and low investment. Then, DDL Construction's main business is real estate projects and public construction projects, and most of the engineering grades are low, the competition is fierce, and the profits are thin. The professional engineering business with high technical content such as building intelligence and landscaping and higher profit margins is relatively low. Further, from the perspective of customer allocation, DDL Construction Company customers are concentrated in real estate developers and local governments. Such customer distribution will bring Evergrande's operational risks. Once the customer environment changes greatly, the company's operations will become extremely passive. Finally, DDL company concentrates on the local market and the market layout is unreasonable.

Opportunities. First, China's construction industry has strong laws and regulations, and the political and legal environment is relatively good. The Inner Mongolia Autonomous Region, where DDL Construction Company is located, has implemented a series of local regulations in addition to implementing relevant national laws and regulations. Further standardizing the local construction industry and promoting its healthy development will create a good market environment for DDL Construction Company. Second, China has introduced many policies to support and promote further transformation and upgrading of the construction industry. This provides an excellent opportunity for DDL Construction Company to combine its own characteristics, adjust the process business structure, and combine its own characteristics to carry out transformation and upgrading. Third, the new urbanization and the Belt and Road strategy bring new market opportunities. Lastly, many construction companies, especially small and medium-sized construction enterprises, still use traditional construction techniques, and they have not changed their production and management concepts in a timely manner. If DDL construction companies can adjust their business structure in time, further improve the technological level of construction technology, then DDL can get considerable technical advantages and reduce costs to get more markets.

Threats. DDL also faces the following environmental threats. Firstly, In recent years, the rate of economic growth has begun to slow down, and the growth 
rate of the total economy and fixed investment has declined. Overall, this will undoubtedly reduce a considerable part of the construction market opportunities. Secondly, DDL faces fierce market competition. Then, the regulatory mechanism of China's construction industry is still not sound enough, and the construction of market supporting mechanisms such as credit management has not made much progress. Therefore, there are still some unfavorable phenomena such as qualifications, low-price bids, and subsidy construction, which will also affect the market. Lastly, the prices of raw materials in China's construction industry have risen to varying degrees with changes in labor costs and supply and demand, increasing the cost of enterprises.

\section{Suggestions}

Through analysis, this paper puts forward some suggestions for DDL Company's future development.

\subsection{Competitive Strategy Choice: Focus on Differentiation}

Focusing on differentiation strategy refers to the unique positioning of enterprises and competitors, and the uniqueness of products, technologies and services, and the formation of unique capabilities within a specific market.

Internally, compared with other companies in the industry, DDL Construction Company has weaknesses such as small scale, weak capital strength and poor operating efficiency. In the broad construction industry, the company cannot meet the differences of all customers in the market. Demand, and it is impossible to achieve a competitive advantage by reducing costs by scale. Therefore, companies must accurately analyze the different needs of customers in various market segments to segment the market. In addition, the attractiveness of various market segments is very different. Each enterprise also has different resources and business objectives, and it is impossible to meet the diversified needs of all different types of customers at the same time. Therefore, enterprises must focus on one or several market segments as their target market in combination with the advantages and disadvantages of their own resources, and provide higher quality products and services to customers in the target market to gain a competitive advantage.

From the perspective of the external environment, at present, the new urbanization and the Belt and Road strategy has brought new market opportunities to the industry, while the green and intelligent industry new technologies have also brought opportunities for business transformation. Therefore, combined with the SWOT analysis, the existing strength of DDL Construction Company is incapable of vying with the leading enterprises in the industry, and the market is becoming more and more fierce, facing the differentiation strategy of the main competitors facing the overall market, and the cost is not available. In the case of competitive advantage, DDL Construction Company should implement a focused differentiation strategy. 


\subsection{Implementation of DDL Construction Company's Competitive Strategy}

1) Adjustment of organizational structure. Effective implementation of focusing differentiation strategy cannot be separated from the support of scientific system organizational structure. At the same time, organizational structure optimization is a systematic project, aiming at improving the organizational capacity of various departments and effective utilization of enterprise resources.

In view of the characteristics of DDL Construction Company's construction projects which are numerous and complex and complicated in management, a flat matrix organizational structure should be established with the project as the center. The new organizational structure should take various projects as the service center and carry out the diversified management mode of project management, resource allocation and skill training. For the operation of various departments, the mode of business linkage and independent financial accounting should be implemented. To serve various projects, the chief engineer will lead the technical center departments of the company, including the project management department, the technology development department, the safety and quality inspection department and the contract budget department. The deputy general manager will co-ordinate the related functions such as the human resources department, the material management department, the financial management department and the management department. Each project is under the unified command of the management department and forms linkage in business, so as to realize the management mode of financial independent accounting for resource exchange.

According to DDL company's planning demand of focusing on differentiation strategy, enterprise's technological innovation ability and marketing ability are very important. Therefore, the company set up a new technology research and development department, led by the chief engineer, based on the company's existing and future key development of the construction field, actively carry out the research and development of new materials construction technology, to provide support for the company's differentiated construction technology and quality. After adjustment, the organizational structure is clear, the power and responsibility are clear, senior management can have better control over the operation activities, and can be more effective. Good control of project progress and quality. Specifically, the new organizational structure of DDL company is as follows: the project management department is responsible for project schedule control, customer demand communication and contact with external partners (such as labor subcontractors) to ensure the coordination of customer needs and project implementation, and further improve the service difference of DDL company; the technology development department is responsible for project construction guidance and new technology development, which is the product of DDL company. The Ministry of Safety and Quality Inspection is responsible for reviewing the quality of each project and is independent of the Project Manage- 
ment Department and the Technical Department to further ensure the quality of construction products; the Contract Budget Department and the Technical Department cooperate with each other to prepare tenders; the Human Resources Department recruits professionals and staff skills training, and allocates manpower to each project according to the needs of the project; The management department is the carrier of the company to connect with external resources, collect external information and communicate with customers initially, and is responsible for the establishment and maintenance of the company's brand image. Departments are managed according to their business content and nature, which improves the efficiency of management and brings into play the professional management role of functional organizations.

To adjust the organizational structure of DDL company, on the one hand, through the construction of the company's marketing, DDL company's awareness of the local construction industry will be strengthened, and the promotion of the company's business and management capabilities will also deepen customer trust. At the same time, the opening of online platforms such as Weibo and Weixin also expands the channels of communication between enterprises and customers, which can help companies respond quickly to customer needs and industry changes. On the other hand, it is the only way for modern enterprises to improve their operational efficiency and the important means for companies to carry out technological innovation to promote the company's informatization reform and innovative R\&D construction and digitalize the company with information technology. Through this improvement, external DDL company can capture business opportunities more conveniently and timely; internal DDL company can improve the safety and reliability of production, change the disadvantage of inconsistent information in the design, production and circulation links in the past, which is conducive to promoting business process reengineering and organizational structure adjustment, improving the technological content of company products, reducing resource consumption and improving production efficiency.

2) Creating an Effective Control System. The implementation of differentiation strategy is a long period of time. In this process, enterprises will face unpredictable factors such as environmental changes and leadership quality. Without intervention and control, the results of strategy implementation will deviate from the initial goals. In order to ensure the effective implementation of the strategy, enterprises must set up control systems and take necessary corrective measures to ensure the successful implementation of the focused differentiation strategy. Therefore, on the basis of ensuring the efficiency of enterprise operation, the company should set up control system:

One is to set up control nodes for important business links, and to set up examination and approval links for important links which are prone to interest-related and interest entanglement. Taking the procurement business as an example, at present, DDL company's procurement business has not taken mu- 
tual supervision, the division of powers and responsibilities is not obvious, and even some problems such as procurement rebates, repeated reimbursement, increase the company's operating costs, but also have a very negative impact on the image of the enterprise. In the future, the company should take the project as the center. Every link in the process of the project should be responsible for people. The right to quality inspection, settlement and warehousing should be independent, supervise each other, and formulate risk warnings to correct deviations in time. At the same time, stock management should be strengthened, and inventory planning should be rationally planned according to the inflow and outflow rules of past raw materials. For project implementation, fine management should be implemented, such as arranging on-duty inspection and maintenance of daily equipment in the construction process, and shifting of duty personnel to ensure 24-hour business response. In case of emergencies, it is guaranteed to arrive at the scene within 10 minutes and be resolved within the prescribed time according to the accident grade.

Another is to strengthen construction cost management. Construction cost management runs through the whole operation link. Strengthening construction cost management is not only the embodiment of enterprise's price and technological advantages, but also the embodiment of the core competitiveness of construction enterprises. The thinking of cost management should run through the whole project: in the design stage, technicians should conduct in-depth analysis of the project and abandon unnecessary functions to reduce the cost; in the bidding stage, they should choose appropriate contract mode and contracting mode according to the characteristics of different projects; besides the construction cost, they should also consider the operation and maintenance costs; in the construction stage, they should pay attention to quality and cost. At the maintenance stage, reasonable maintenance schemes are formulated with the lowest total cost as the goal to provide the most cost-effective repair services.

3) Establish and cultivate corporate culture. For DDL Construction Company, in order to ensure the successful implementation of the focus differentiation strategy, it is necessary to further strengthen the company's cultural construction, including science and technology culture, innovation culture construction and institutional culture construction. The first is the construction of science and technology culture, the strength of science and technology determines the destiny of enterprises, and the organizations that lack attention to science and technology will be out of the pace of the times. The improvement of scientific and technological capabilities is not a day's work, and it needs to be supported by the members of the organization. Therefore, DDL should pay attention to the construction of corporate science and technology culture, attach importance to the scientific and technological culture of enterprise employees, regularly conduct scientific and technological culture training, formulate each training theme, train employees to update their learning ability of scientific and technological knowledge, optimize their knowledge structure, and educate employees. If you only pay attention to the immediate interests, only the pursuit of temporary 
turnover and sales profits will lose long-term competitiveness. With regard to the construction of innovation culture, innovation is the key driving force for enterprise development in the current rapid iteration of products and technologies. It is related to the long-term operation and prosperity of enterprises. The construction of innovation culture is the key to the maturity of enterprises and has a profound impact on the development of enterprises. In the construction of innovative culture, DDL should abolish the formalism of the framework, stimulate the creative inspiration of employees; improve the effective incentive mechanism for talents, give material and spiritual incentives to innovative talents; boldly introduce talents to manage enterprises, and assign responsibility So that they can make their own decisions according to the needs of market competition to adapt to changes in the market. At the same time, the company should also actively carry out institutional culture. The system clarifies the rights and obligations of employees and standardizes the company's business processes. Only by standardizing and refining the company's rules and regulations, can the company's future planning and business philosophy be implemented smoothly. In the process of building corporate culture of DDL Construction Company, the following aspects should be noted:

First, strengthen corporate culture. Since its establishment, DDL Construction Company has been adhering to the business philosophy of "honesty, science and technology, and construction of fine products". Under the influence of this culture, DDL Construction has continuously strengthened its quality awareness and safe and civilized construction management, and built quality projects for the society. In the future development of the enterprise, DDL Construction Company should always put the core culture of the enterprise in an important position, not on the wall. The company's leadership set an example by taking the lead and role model of leadership, from top to bottom, to form a company with its own unique cultural heritage. At the same time, paying attention to the safety of employees' construction, the company should closely follow the principle of "safety first, prevention first, comprehensive management", and regularly carry out safety knowledge education and safety operation training for employees.

Second, people-oriented, strengthen the company's human care. The company's cultural construction can not only stay in the mouth, but in the daily work and life. When carrying out enterprise reform, the management should stand in the perspective of employees, listen to the voices of employees, and solve the problems of employees. For example, for the relatively dangerous nature of the construction industry, the full coverage of industrial injury insurance is implemented. This measure is also beneficial to enterprises. Recruitment, reflecting the company's humane care. Further, flexible adjustment of work life and spiritual life, increase team entertainment activities, enrich employees' lives, meet the spiritual needs of all employees, enable cross-sector employees to know each other and strengthen employees' sense of identity, destiny and honor.

Third, mobilize employees to participate in the construction of corporate culture. Employees make the main body of the company's operation, and also the 
main force in the shaping and practice of corporate culture. A good corporate culture is inseparable from the joint efforts of all members. DDL Construction Company can adopt regular training methods to conduct case analysis on benchmark enterprises in the industry, introduce advanced management concepts at home and abroad, give full play to ideological education, and optimize employee knowledge structure. The management should also strengthen communication with employees, avoid corrupt bureaucracy, eliminate the hierarchy of rules and regulations, and stimulate employee creativity. Create a good atmosphere for equal communication and encourage employees to make suggestions within the company, give employees the space for free development, and expand the company's information contact points, which is conducive to the long-term development of the company.

\section{Discussion}

\subsection{Implications for Enterprises}

Based on the comprehensive analysis of the macro environment and internal resource capabilities faced by DDL Construction Company, this paper proposes a competitive strategy suitable for enterprise development based on the relevant theories of strategic management, and draws the following conclusions:

1) In terms of the external environment, DDL Construction Company faces enormous opportunities and threats. The stability of the political and legal environment is the basis of business management, and the promotion of many industries and the promotion of new urbanization have brought opportunities for the development of construction enterprises. The development of new construction technologies has also brought a critical period for business upgrading and transformation. At the same time, DDL Construction Company is also facing the threat of slowing macroeconomic growth, fierce competition in the local market, imperfect industrial regulatory mechanisms and rising construction costs.

2) In terms of internal environment, DDL has a good growth momentum and high engineering quality, and has accumulated a high reputation in the industry. At the same time, compared with competitors, the company has always insisted on science and technology and has better performance, innovative mind. At the same time, due to the short time of the establishment of the company, there are still weak items such as small scale, weak strength and relatively lack of management.

3) Combining the evaluation of DDL company's opportunities, threats, strengths and weaknesses, in the strategy formulation, using SWOT matrix for strategic analysis, DDL is proposed as the second-level construction enterprise for housing general contracting based on project construction. Focus on the differentiation strategy, deepen the Chifeng City and surrounding markets, focus on high-end projects, and increase the difference in quality, products and services and technological innovation with competitors to win competitive advantage. Strengthening quality control includes human control, mechanical equip- 
ment control, material quality control, construction method control and construction environment control; when implementing product/service differentiation strategy, it also follows policy guidance and makes full use of government financial assistance. Support the optimization of business structure, realize product intelligence, green upgrade and transformation, and provide quality service centered on customer service; in technological innovation, always adhere to the direction of scientific and technological progress and innovation, pay attention to and strengthen science and technology, environment and green construction, organic integration, the application of new technologies, new processes, new materials in engineering construction.

4) In terms of strategy implementation, based on the focus differentiation strategy of DDL Construction Company, it provides specific strategic implementation suggestions from three aspects: organizational structure adjustment, control system establishment and corporate culture cultivation. First, from the adjustment of organizational structure, strengthen the company's marketing construction, improve brand exposure and influence; strengthen information construction, improve the company's operational efficiency; strengthen research and development of technical departments, achieve technological innovation differentiation; improve customer relationship management Strengthen the awareness of the organization's services. Secondly, improve the company's control system, set up control nodes in important business links, and develop risk warnings; improve the company's talent recruitment and training system, build a quality talent team; improve the company's compensation and welfare system, improve employee happiness and organizational identity; strengthen construction Cost management to increase corporate prices and technological advantages. Finally, in the cultivation of corporate culture, strengthen corporate culture propaganda; people-oriented, strengthen corporate humane care; mobilize employees to participate in corporate culture construction.

\subsection{Limitations}

This paper takes DDL Construction Company as the research object, and puts forward the strategic decision of focusing on differentiation after comprehensive analysis of the internal and external environment of the enterprise, which provides certain theoretical guidance for the future development of DDL Construction Company. However, due to space limitations and author's ability, the paper still has certain limitations:

1) Limitations of data analysis. In the analysis process of DDL Construction Company, the data is mainly based on the company's financial statements, lacking on-the-spot investigations on the company's brand image, upstream and downstream customer relationships and other factors. The analysis is mostly theoretical and lacks certain data support, leading to the conclusion that there is a deviation in the actual situation.

2) Limitations of the strategic perspective. The "One Belt, One Road" strategy 
formulated by the current state has led to the transfer of domestic excess capacity to Asian and African countries with weak infrastructure, which has injected new vitality into the construction industry. In this context, how DDL Construction Company, which focuses on expanding green building and intelligent building business, will use this opportunity to develop an overseas competitive strategy. This practical issue has not been discussed in this paper.

In the future, the author will conduct further in-depth research within the enterprise, conduct interviews and questionnaire surveys of company employees and management personnel, collect first-hand enterprise data, and ensure the completeness and scientificity of the data.

DDL's development and development conference has experienced a long time span. During this period, the company's internal and external environment is expected to undergo major changes, and the effectiveness of focusing on the differentiation strategy will inevitably be affected. Therefore, the company should promptly adapt to environmental changes, seize market opportunities, and flexibly adjust strategies. In addition to the research content of this paper, I believe that at least the following two issues have the value of further research: a) How to use BOT (construction-operation-one handover contract) and EPC (design) in the current domestic legal environment $\mathrm{A}$ new business model such as procurement and construction general contracting, PMC (project management general contracting) and PPP (public sector and enterprise cooperation mode) to achieve a win-win situation between the owner and the contracting enterprise is the current and future period of domestic construction enterprises. The topics should be actively explored within. b) How to help traditional enterprises to use Internet thinking, not to stick to tradition, to achieve their own structural adjustment and transformation is a major direction of future strategic research. Calling for more research in the future can focus on the strategic transformation of traditional enterprises and provide more ideas for the development of traditional enterprises.

\section{Conflicts of Interest}

The author declares no conflicts of interest regarding the publication of this paper.

\section{References}

[1] Porter, M.E. (2008) Competitive Strategy: Techniques for Analyzing Industries and Competitors. Simon and Schuster, New York.

[2] Porter, M.E. and Millar, V.E. (1985) How Information Gives You Competitive Advantage. Harvard Business Review, 63, 149-160.

[3] Porter, M.E. (1993) The Competitive Advantage of Nations. Harvard Business School Management Programs, Cambridge.

[4] Hao, M. (2017) Strategic Management 50 Years: Development Thread and Dominant Paradigm. Foreign Economics and Management, No. 39, 15-32.

[5] Nie, J. (2002) Value Chain Analysis in Strategic Cost Management. Journal of Ac- 
counting, No. 7, 13-14.

[6] Hines, P. (1998) Strategic Cost Management and Value Chain. ITP Company, 35-36.

[7] Wu, C.Z. (2010) A Review of the Development of China's Strategic Management Research. Nankai Management Review, No. 6, 25-40.

[8] Dong, G.M. and Lei, L. (2014) Enterprise Knowledge Transfer Strategy under Competitive Conditions and Its Impact on Industrial Evolution. Journal of Management, No. 8, 1246-1252.

[9] Lan, H.L. (2015) Enterprise Strategic Management: Commitment, Decision and Action. Journal of Management, No. 12, 664-678. 